\title{
9 La narrativa en el marco de esta investigación: enfoque, metodología y corpus
}

Como lo hemos mencionado en la introducción, los objetivos de la parte empírica son, por un lado, reconocer en las narrativas de entrevistados que estudiaron con los LTG hasta qué punto se reflejan los MCI y los ideologemas planteados por los manuales. Pero, de manera más específica, nos interesa identificar el posicionamiento que los entrevistados adoptan frente al discurso y prácticas del sistema escolar con el que fueron educados. Esto implica que, además de observar el trabajo identitario que realizan los entrevistados a nivel micro (localmente), nos interesa especialmente estudiar cómo estas narrativas remiten y están condicionadas por procesos a nivel macro, en este caso, por las ideologías vehiculadas por los libros de texto y el sistema educativo mexicano. Por esta razón, el enfoque sociointeraccional propuesto por De Fina y Georgakopoulou (2008, 2015) ha resultado ideal para abordar el análisis. Como las autoras, sostenemos que las narrativas pueden ser adaptadas estratégicamente para expresar identidad grupal, reafirmar y legitimar aspectos que componen dicha identidad. Al ser parte de comunidades de práctica, las narrativas pueden ser recicladas y recontextualizadas. Además, muchas de ellas pueden fomentar la circulación de discursos dominantes, lo cual contribuye al reforzamiento y al mantenimiento de la hegemonía de estos discursos (Kiesling 2006, p. 280).

En este trabajo la narrativa es considerada como un modo de pensamiento a través del cual se captura una experiencia, se reelabora, se reproduce y se reflexiona sobre ella. En este sentido, la narrativa nos permite conocer e interpretar el mundo (Bruner 1986), concebir nuestra existencia y construir nuestra identidad. En efecto, la narrativa resulta un espacio de configuración del “yo”, ya que nuestra identidad es construida mediante las historias que contamos a otros dentro de la interacción. Así pues, la construcción y el despliegue identitarios dependen de la interacción local, pero también de la existencia de mecanismos cognitivos que posibilitan, por ejemplo, la categorización social o procesos inferenciales de información. Estamos hablando, por ejemplo, de conocimiento compartido organizado en guiones, marcos (frames) o modelos cognitivos idealizados, los cuales son adquiridos, convencionalizados y aplicados en el proceso de (auto)categorización identitaria.

En suma, consideramos la narrativa como un tipo de discurso que refleja una experiencia (pasada, presente o hipotética), la cual es digna de ser contada (tellability) porque significa algo para el narrador a un nivel emocional o cumple una función específica según el contexto interaccional y la intención del hablante. Tomaremos en cuenta, pues, las narrativas de experiencias personales 
(o narrativas experienciales), que pueden tener o no la estructura de la narrativa canónica laboviana; narrativas testimoniales que implican la observación de sucesos ocurridos a otros (Fludernik 2003, p. 252); narrativas de experiencia indirecta, relatadas en tercera persona que cuentan la experiencia de otros (Fludernik 2003, p. 252); narrativas habituales que tratan eventos que ocurrieron una y otra vez y en consecuencia no hay un clímax accional (Riessman 1993); narrativas hipotéticas que cuentan acontecimientos que no han sucedido pero que podrían haber ocurrido (Riessman 1993). Asimismo, consideraremos las llamadas grandes narrativas (master narratives), término que ha sido usado indistintamente como discurso dominante especialmente dentro de los ECD (De Fina 2017, p. 239). Sin embargo, en este trabajo haremos la distinción: hablaremos de discurso dominante, Discurso con " $D$ " mayúscula o discurso hegemónico para referirnos a fenómenos de macronivel que vehiculan determinada ideología y que han sido aceptados y asumidos por un grupo. Las grandes narrativas en cambio, son historias concretas que también son dominantes, ya que circulan a través de los medios, son aceptadas y repetidas por la gente, es decir, se vuelven parte de la cotidianidad de una comunidad. Finalmente, tomaremos en cuenta narrativas que no cumplen la estructura prototípica, como las referencias narrativas y las pequeñas historias (Georgakopoulou 2006; 2015).

\subsection{Pautas metodológicas y corpus}

Para la elicitación de narrativas hemos adoptado como herramienta metodológica la entrevista semidirigida, ya que como otros investigadores (Briggs 1986; Mishler 1986; Elliott 2005; Riessman 1993, 2008; De Fina 2009; De Fina \& Perrino 2011; Wortham et al. 2011; Koven 2011, etc.) consideramos que la entrevista no es un contexto de investigación "antinatural", sino que, por el contrario, es un espacio interaccional que incita la (co)construcción y la negociación de identidades.

Se optó por la entrevista semidirigida para poder dar libertad de expresión a los entrevistados sin obligarlos a responder a preguntas cerradas que limitarían la aparición de narrativas. La entrevista pasó por un proceso de pilotaje realizado tres meses antes, el cual nos permitió identificar las preguntas que podrían elicitar más narrativas, así como aquellas que podrían representar incomodidades o malentendidos.

Nuestro corpus está conformado por 20 entrevistas semidirigidas que corresponden a 5 individuos por cada generación de libros. Cada entrevista tiene una duración de entre 30 y 40 minutos. Las entrevistas se realizaron en la casa de los entrevistados para su comodidad y todas fueron realizadas por la autora 
de este estudio. Al inicio se dio una explicación a los entrevistados sobre la naturaleza científica de la investigación y al final se les proporcionó un documento donde firman su consenso para la utilización de su entrevista para fines científicos. Las preguntas fueron diseñadas de acuerdo a las lecturas e imágenes de los libros, las cuales sirvieron de input para las respuestas y la elicitación de narrativas. De este modo, se comenzó preguntando a los entrevistados sobre algún recuerdo que tuvieran sobre sus libros para después mostrarles el material con el que estudiaron en primero de primaria. Los libros fueron mostrados de manera digital mediante un dispositivo tipo tableta. La entrevista fue grabada con una grabadora de voz TASCAM DR-05. Aunque no siempre fueron las mismas preguntas o no siguieron siempre el mismo orden, estas giraron en torno a este esquema:

1) Explicación: se refiere al entrevistado que la investigación es sobre los contenidos, los valores y las tradiciones que presentaban los libros de texto.

2) Calentamiento: para hacer que el entrevistado empiece a recordar y no perciba que es un interrogatorio de conocimientos generales se le hacen preguntas como “ ¿Te acuerdas de tu primaria? ¿Cómo era? ¿Te acuerdas de algún maestro? ¿Te acuerdas de alguno de tus libros o de alguna lectura o imagen?".

3) Observación del libro: se muestra el libro y se pide al entrevistado que lo hojee. Mientras el entrevistado ve el libro de su generación se le pregunta “¿Te viene algún recuerdo a la mente viendo el libro?”.

4) Lectura sobre los honores a la bandera: en cada generación de libros aparece una referencia a este tema (LL 1960, pp.174-177; EE 1972, pp. 219-221; MLP II 1980, pp. 384-385; LI 1994, pp. 95, 172). Se hace ver esta lectura y se le pregunta al entrevistado: “¿Me podrías contar cómo eran las ceremonias en tu escuela? ¿Te gustaban? ¿Alguna vez participaste haciendo algo especial?”.

5) Lectura sobre la fiesta del la Independencia de México: se muestra al entrevistado la lectura (LL 1960, pp.184-185; EE 1972, pp. 213-214; MLP II 1980, pp. 464-466; LI 1994, pp. 24-25), en seguida se comenta que el libro también habla de otras ceremonias y festividades como la celebración de la Independencia y se pregunta si en su escuela se festejaba y si alguna vez participó.

6) Leyenda mexicana: se le pregunta al entrevistado si conoce y si recuerda alguna leyenda o cuento mexicano que apareciera en los libros (o uno de su elección) y se le pide que lo cuente.

7) Historia de México: para que esta pregunta no se entienda como un examen de historia, lo cual podría hacer sentir en dificultad al entrevistado, se le dice que los libros de primero hacen breves y escasas referencias a la historia nacional y se busca una lectura. Al mismo tiempo se le pregunta cuál es la parte de la historia de México que más le gusta y se le presenta una situación hipotética preguntándole que si un amigo extranjero visitara el país y le 
preguntara por la historia mexicana, qué parte le contaría. Esta pregunta tiene el objetivo de evocar el marco cognitivo de EL OTRO para así promover la activación del marco de autorrepresentación grupal.

8) Preguntas adicionales: las siguientes dos preguntas se realizan casi para finalizar la entrevista: a) ¿Me podrías decir las primeras 5 palabras que te vienen a la mente con el tema "la mexicanidad"? b) Si tuvieras que hacer un cartel sobre "lo mexicano" ¿qué imágenes pondrías? A pesar de que somos conscientes de que estas preguntas no elicitarían narrativas (aunque en algunos casos ocurrió lo contrario), decidimos incluirlas con el objetivo de conocer los elementos concretos que conforman la identidad nacional para los entrevistados, así como conocer la relevancia que tienen para ellos, según el orden de mención.

9) Imagen "La Patria”: la última pregunta de la entrevista surge a partir de un estímulo visual. Se presenta al entrevistado la imagen que cubre las portadas de los libros de los años sesenta y se le pregunta si la conoce y si le gusta. Aunque aparentemente esta pregunta no elicitaría narrativas, nuestra prueba piloto demostró lo contrario.

Las entrevistas fueron transcritas completamente. Para ello se utilizó el software profesional de transcripción multimodal ELAN, el cual es muy utilizado en la investigación dentro de las ciencias sociales. Las ventajas que esta herramienta proporciona son varias: por un lado, su modelo basado en niveles permite la transcripción de los turnos de habla del entrevistado y del entrevistador en dos líneas distintas que corresponden exactamente con el tiempo de su producción. Por otro lado, se pueden crear líneas "hijas" en las cuales reprodujimos la transcripción de cada uno de los participantes, pero con marcas del lenguaje oral de tipo prosódico y kinésico. Las líneas principales donde la transcripción es literal nos ofrecen una visión cuantitativa, ya que a través de ellas se pudieron contabilizar ítems. Las líneas "hijas”, en cambio, permitieron hacer un análisis cualitativo, que en este estudio ayudó a develar el funcionamiento y relevancia de ciertas marcas de la oralidad. Las convenciones que se siguieron para la transcripción en las líneas secundarias están basadas en la propuesta de Jefferson (1984) con algunas modificaciones. Las normas de transcripción se pueden encontrar en el apéndice de este trabajo.

Una vez hechas las transcripciones se prosiguió con la identificación y clasificación de todas las narrativas aparecidas en cada una de las entrevistas para su posterior selección, análisis y comparación con las narrativas del resto de los entrevistados.

En cuanto a la presentación de los extractos de transcripción, hemos utilizado la versión generada por el mismo programa ELAN, y hemos respetado el 
número de líneas con respecto al momento en que estos fragmentos aparecen en la entrevista.

Al finalizar los capítulos de análisis de narrativas presentamos un gráfico (Gráfico 5) en el cual se puede apreciar la recurrencia de ciertos vocablos pertenecientes a los marcos cognitivos de IDENTIDAD MEXICANA propuestos por los libros y que aparecieron en el discurso de los entrevistados. A partir de este gráfico se puede hacer una comparación con los esquemas radiales que presentamos al final de los capítulos 4, 5, 6 y 7 correspondientes al análisis del MCI de IDENTIDAD MEXICANA construido por los LTG. 
